\title{
Innovative ionic liquids as functional agent for wood- polymer composites
}

\author{
Majka Odalanowska $\cdot$ Andrzej Skrzypczak $\cdot$ Sławomir Borysiak $\mathbb{E}$
}

Received: 11 April 2021 / Accepted: 12 September 2021/Published online: 22 September 2021

(C) The Author(s) 2021

\begin{abstract}
Chemical modification of lignocellulosic fillers is a hydrophobization process that has been used for years in the production of wood-polymer composites (WPCs). However, finding new, more effective modifiers is still a big challenge and remains the subject of much research. This study involved the chemical modification of wood with the use of newly designed ammonium and imidazolium ionic liquids containing reactive functional groups. The effectiveness of the modification was confirmed using FTIR and XRD techniques. The effect of modification of wood on the supermolecular structure and morphology of wood-polymer composites was investigated by $\mathrm{X}$-ray diffraction, hot stage optical microscopy and differential scanning calorimetry. A significant influence of the modifier structure on the shaping of polymorphic varieties of the polymer matrix was
\end{abstract}

demonstrated. The chemical modification also had significant effect on the nucleating properties of the wood fillers, which was confirmed by the determined crystallization parameters (crystallization half-time, crystallization temperature, crystal conversion). Moreover, the formation of a transcrystalline PP layer was noticed, which showed a large variation depending on the structure of the used ionic liquid. The obtained results correlated very well with the results of mechanical tests. It has been shown that it is possible to precisely design an ionic liquid containing a reactive functional group capable of interacting with hydroxyl groups of cellulose molecules. Moreover, the possibility of functionalizing the lignocellulosic material with innovative ionic liquids without the need to use organic solvents has not been demonstrated so far.

M. Odalanowska · A. Skrzypczak · S. Borysiak ( $\bowtie)$

Faculty of Chemical Technology, Institute of Chemical

Technology and Engineering, Poznan University of

Technology, Berdychowo 4, 60965 Poznan, Poland

e-mail: Slawomir.Borysiak@put.poznan.pl 


\section{Graphic abstract}

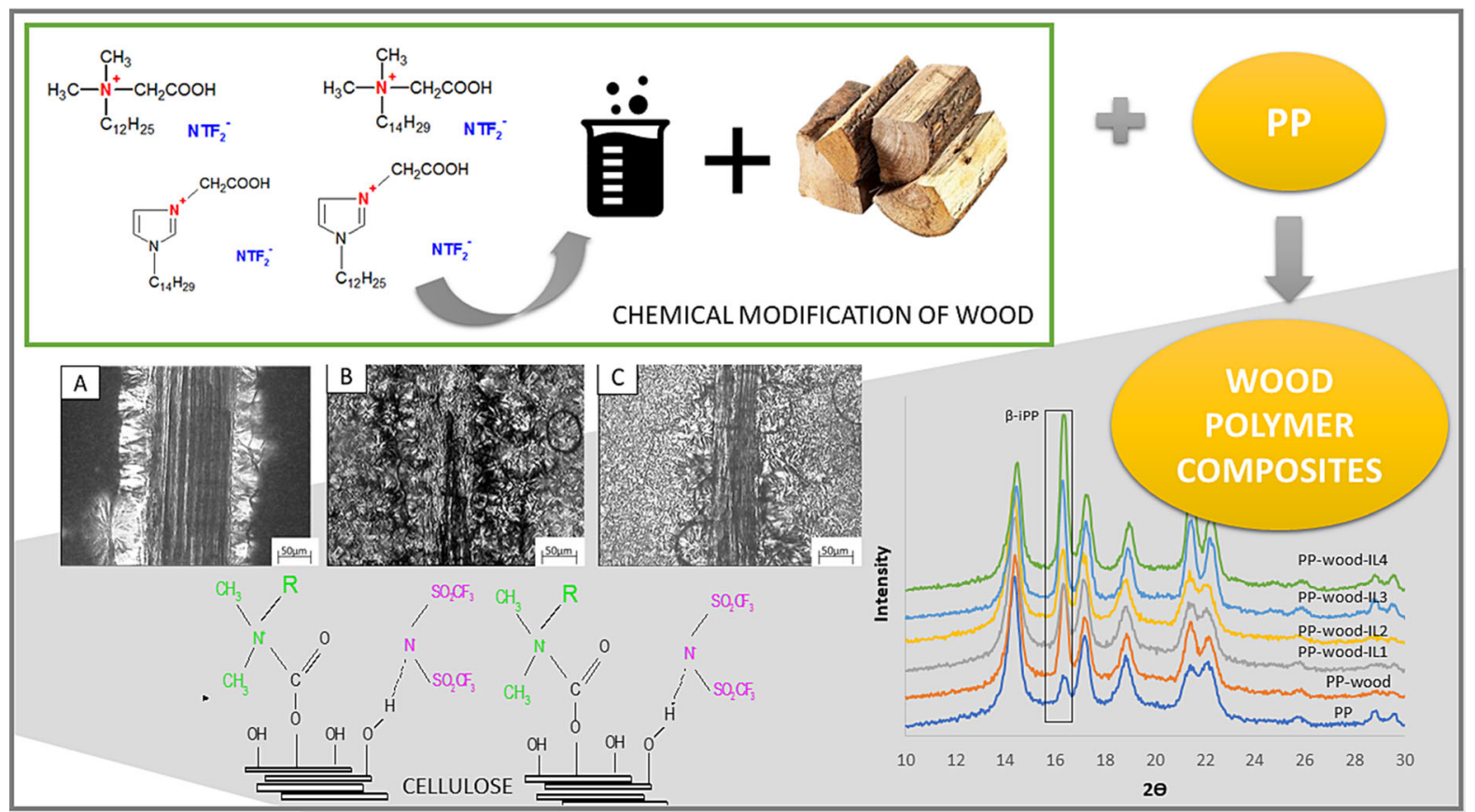

Keywords Wood/Polypropylene composites . Wood modification · Ionic liquids · Supermolecular structure $\cdot$ Nucleation activity

\section{Introduction}

Composites containing lignocellulosic fillers are an ideal alternative to fully synthetic plastics and perfectly fit into ecological trends (Sabu Thomas, P. M. Visakh 2012; Sandberg et al. 2017; Cao et al. 2020; Zhu et al. 2020). They gained popularity owing to very good mechanical properties, weather resistance, and low price (Bledzki and Gassan 1999; Mohanty et al. 2000; Ashori 2008; Arwinfar et al. 2016; Alan and Ada Pui Yan Hung 2017; Martins et al. 2017).

One of the most commonly used lignocellulosic fillers is wood, a material with a complex anatomical structure, mainly composed of cellulose, hemicellulose and lignin. The synergistic effect of these components in wood structure is responsible for its attractive physicochemical properties. The main component of wood-cellulose is made of a long chain of repeating D-glucose units, linked by $\beta(1 \rightarrow 4)$ glycosidic bonds. Moreover, its molecules contain numerous hydroxyl groups $(-\mathrm{OH})$ responsible for the occurrence of strong hydrogen interactions between the chains. However, the polar structure of cellulose is also the main reason for its incompatibility with hydrophobic polymer matrix (Pandey 1999; Oksman et al. 2003; Inagaki et al. 2010; Rojas 2016). Problems related to obtaining uniform dispersion of the filler in the matrix and insufficient interfacial adhesion arise during the production of biocomposites. Therefore, it is necessary to consider performing an additional compatibilization process (Bledzki and Gassan 1999; Nuñez et al. 2003; Borysiak 2013a; Thakur et al. 2014b; Hokkanen et al. 2016; Herrera-Díaz et al. 2018). Many methods of chemical modification of lignocellulosic components in terms of improving filler-polymer interfacial adhesion are known, and include: esterification reactions (Kazayawoko et al. 1999; Nuñez et al. 2003; Abdulkhani et al. 2014), acetylation reactions (Tserki et al. 2005; Ashori et al. 2014; Mantanis 2017) isocyanates reactions (Joly et al. 1996; Ellis and O'dell 1999; Shang et al. 2013), and silanes reactions (Salon et al. 2007; Thakur et al. 
2014a; Hasan et al. 2019). However, despite their high price, their effectiveness is limited, and these reactions involve the use of a significant amount of toxic organic solvents (Ichazo et al. 2001; Nachtigall et al. 2007; Kalia et al. 2009; Dányádi et al. 2010; Frone et al. 2013; Sandberg et al. 2017).

An interesting alternative is to replace commonly used modifiers requiring organic solvents with specially designed ionic liquids (Croitoru and Patachia 2016; Borysiak et al. 2018). Ionic liquids (ILs) are a relatively new group of compounds, included in the so-called green chemistry. They are composed of an organic cation and a small-molecule anion. Their characteristic features are low vapor pressure and melting point which is usually below $100{ }^{\circ} \mathrm{C}$. They are called innovate compounds because there is almost unlimited possibility for their precise design and synthesis (Earle and Seddon 2002; Plechkova and Seddon 2008). In addition, they have the ability to dissolve both organic and inorganic compounds. Ionic liquids have been applied in many industries, primarily as non-toxic solvents for many reactions (Huddleston et al. 2001; Kilpeläinen et al. 2007; Li et al. 2008; Sun et al. 2009; Anugwom et al. 2012; Isik et al. 2014). For the first time ionic liquids as cellulose solvent were used by Swatloski in 2002. Swatloski used ionic liquids containing 1-butyl-3-methylimidazolium cation substituted with anions of different structure (Swatloski et al. 2002). Also many other works have investigated the influence of the structure of ionic liquids on the efficiency of cellulose dissolution process (Vitz et al. 2009; FitzPatrick et al. 2012; Berga et al. 2020). Subsequent literature (Pernak et al. 2004; Zabielska-Matejuk et al. 2015; Feder-Kubis et al. 2019) described the use of ionic liquids as wood impregnating agents. Among others, 3-alkoxymethyl1-methylim-idazolium tetrafluoroborates and hexafluoro-phosphates were used for the preservation of Scots pine boards. The work showed excellent ability of the compounds to penetrate the wood and their very good fungicidal properties (Pernak et al. 2004).

Another research approach suggested the use of ionic liquids as a reaction medium during cellulose functionalization. Many ionic liquids have been proposed to replace commonly used organic solvents. Esterification reactions have been successfully carried out using i.a.1-allyl-3-methylimidazolium chloride $([$ Amim $]+\mathrm{Cl}-)$ (Wu et al. 2004), 1-N-butyl-3methylimidazolium chloride $\left([\mathrm{C} 4 \mathrm{mim}]^{+} \mathrm{Cl}^{-}\right)($Heinze et al. 2005), and 1-ethyl-3-methyl-imidazolium acetate ([EMIM $\left.]^{+} \mathrm{OAc}^{-}\right)($Hinner et al. 2016). The work of Kakko et al. presented the possibility of obtaining cellulose acetate using ionic liquid (1,5-diazabicy- clo [4.3.0] non-5-ene acetate $([\mathrm{DBNH}]+[\mathrm{OAc}]-)$ as solvent. The reagent system, which was used, was characterized by high efficiency in the synthesis of cellulose acetate. Additionally the byproducts and residual solvent were shown to be capable of regeneration and recycling (Kakko et al. 2017).

Another direction of research is the application of ionic liquids as direct wood modifiers without the need to use other chemical compounds. This solution has many advantages, the most important of which is that no organic solvents are needed. In our recent work (Borysiak et al. 2018), didecyldimethylammonium bis(trifluoromethylsul- fonyl)imide was used as a modifier of pine wood. The modification reactions were based on the interactions of the ionic liquid anion with the hydroxyl groups of cellulosic materials. In this study, the reactions were shown to be highly efficient and effective. It was found that chemical modification of wood influenced the course of crystallization of polymer matrix. An improvement in the strength properties of the composites containing the modified lignocellulosic filler was observed, which was explained by an improvement in the interfacial interactions between the components. Successful wood modification using commercial ionic liquids methyltrioctylammonium bis(trifluoromethylsulfonyl)imide (MTOIm) and trihexyltetradecylphosphonium bis (2,4,4-trimethylpentyl) phosphinate (TTDPP) without the use of a solvent is also reported in the work of Croitoru et al. (Croitoru et al. 2018). The obtained hydrophobized fillers were then used to produce wood/HDPE composites.

However, it is worth noting that the use of chemically modified wood as a filler for polymer matrices does not always guarantee the achievement of improved physicochemical properties of composite materials (Borysiak 2012; Paukszta and Borysiak 2013; Thakur and Thakur 2014; (Robin and Breton 2001; Kaboorani et al. 2008; Arwinfar et al. 2016; Tufan et al. 2016; Sandberg et al. 2017). The necessary condition is to obtain strong interfacial polymer-filler interactions. Therefore, many works deal with the study of phase boundary phenomena (Nachtigall et al. 2007; Dányádi et al. 2010; Borysiak 2013a; Petrič 2013). Particularly important is the analysis of the 
nucleation activity of the surface of lignocellulosic fillers, e.g. by the formation of transcrystalline structures (TCL).This phenomenon is highly desirable because it leads to an increase in the interactions between the filler and the polymer matrix, which consequently determines an improvement in the strength characteristics of composite systems (Varga 1992a; Wang and Liu 1999; Amash and Zugenmaier 2000; Zafeiropoulos et al. 2001; Borysiak 2013a). In addition, increasing the nucleation ability of the filler surface has a significant effect on reducing the processing cycle times of polymer composites, which determines the economy of the process.

In the present work, ionic liquids containing active functional groups capable of reacting with cellulose and also containing long alkyl substituents compatible with polymer chains were designed and synthesized for the first time. The innovative ionic liquids provided the possibility to functionalize and simultaneously hydrophobize cellulose without the use of any solvents or additional organic modifiers, which has not been reported in the literature so far. The aim of this work was to analyze the influence of the structure of the ionic liquids used for wood modification on the structure and properties of the obtained composite materials.

\section{Experimental}

\section{Materials}

In this study, isotactic polypropylene (iPP) with trade name Moplen HP456J (MFR230 ${ }^{\circ} \mathrm{C} / 2.16 \mathrm{~kg}-3.4 \mathrm{~g} /$ $10 \mathrm{~min})$ manufactured by BasellOrlen Polyolefins (Plock, Poland) was used as a matrix.

The pine wood (W) (Pinus silvestris) used for the modification came from the company ForestryKaminska (Poland). Before reaction, the wood was cut and sieved through a FRITSCH Pulverisette 19 cutting mill with a rotor speed of $2800 \mathrm{rpm}$. The particle size ranged from 0.5 to $1.0 \mathrm{~mm}$. Pine wood was dried at $70{ }^{\circ} \mathrm{C}$ in a circulating air oven for $24 \mathrm{~h}$. The moisture content was less than $1 \mathrm{wt} \%$. The raw material was used for the chemical modification process.
Synthesis of designed ionic liquids

In this study, four novel ionic liquids containing a functional group in the form of a carboxyl group were synthesized. The aim of the synthesis was to obtain liquids with ammonium and imidazolium cations.

Preparation of ammonium ionic liquids

The ammonium liquids (IL1 and IL2) were obtained by ion exchange reaction by adding bis(trifluoromethane)sulfonimide lithium salt $\mathrm{LiN}\left(\mathrm{SO}_{2} \mathrm{CF}_{3}\right)_{2}$ solution to an aqueous solution of $\mathrm{N}$-dodecyl-Ncarboxymethyl-N,N-dimethylammonium chloride or $\mathrm{N}$-tetradecyl-N-carboxymethyl-N,N-dimethylammonium chloride in a 1:1.1 weight ratio. The resulting solutions were stirred at room temperature for $2 \mathrm{~h}$. The aqueous phase was decanted, and the product was washed with distilled water until chloride ions were no longer detected with the $\mathrm{AgNO}_{3}$ solution.

Preparation of imidazolium ionic liquids

Imidazolium ionic liquids were prepared in a manner analogous to that described above for amine liquids using 1-carboxymethyl-3-tetradecylimidazolium and 1-carboxymethyl-3-dodecylimidazolium chlorides, respectively.

The scheme of the synthesis of ionic liquids is shown in Fig. 1.

The chemical formulas and determinations of the obtained novel ionic liquids are shown in Table 1.

Chemical modification of wood by ionic liquids

Raw pine wood samples were chemically modified using four different ionic liquids. In each case, the modification proceeded in the same way. Dry wood flour was added directly to the ionic liquids in a weight ratio of 1:8. The reactions were carried out at $100{ }^{\circ} \mathrm{C}$ for $6 \mathrm{~h}$ using a mechanical stirrer $(150 \mathrm{rpm})$. After reaction, the resulting suspension was filtered, washed with ethanol and centrifuged to eliminate unreacted ionic liquid. The modified wood was dried in a vacuum dryer at $110{ }^{\circ} \mathrm{C}$ for $30 \mathrm{~min}$. The scheme of wood modification is shown in Fig. 2. 


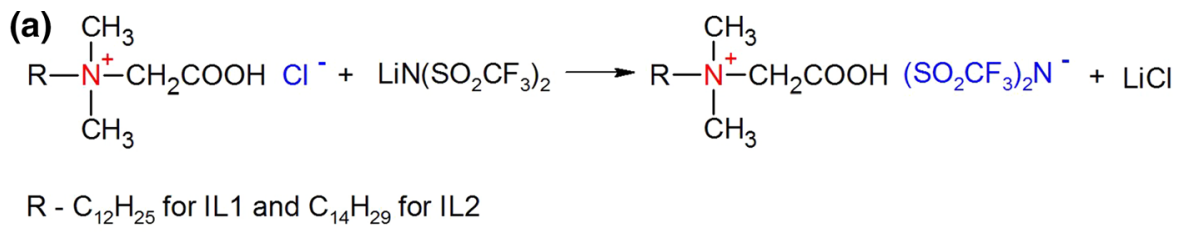

(b)

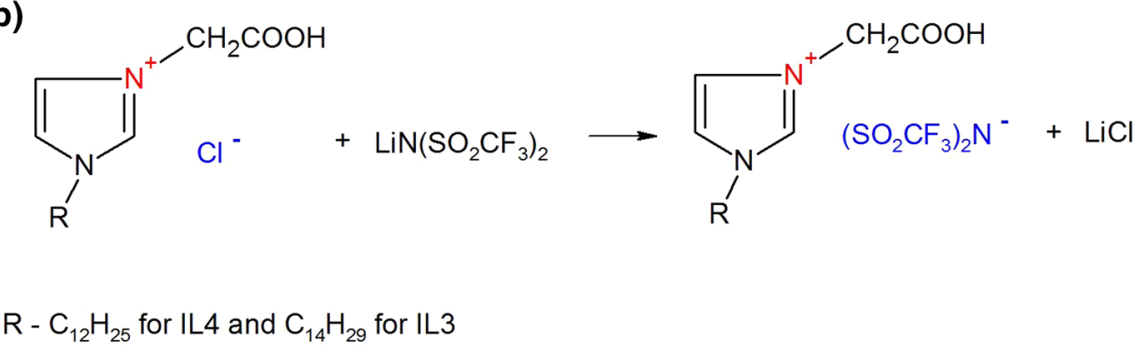

Fig. 1 Scheme of synthesis of a ammonium, b imidazolium ionic liquids

Table 1 Chemical formulas, names, and designations of ionic liquids

\begin{tabular}{lll}
\hline Symbol & Name & N-dodecyl-N-carboxymethyl-N,N-dimethylammonium bis(trifluoromethylsulfonyl)imide \\
\hline IL1 & N-tetradecyl-N-carboxymethyl-N,N-dimethylammonium bis(trifluoromethylsulfonyl)imide & 1-carboxymethyl-3-tetradecylimidazolium bis(trifluoromethylsulfonyl)imide \\
IL4 & 1-carboxymethyl-3-dodecylimidazolium bis(trifluoromethylsulfonyl)imide
\end{tabular}

Preparation of wood-polymer composites

Wood-polypropylene composites containing raw wood and wood modified with ionic liquids were prepared in two steps. Initially, wood particles at $50 \%$ content were introduced into the PP granules using a co-rotating twin-screw extruder (Zamak 16/40 EHD, Poland). The length to diameter ratio $\mathrm{L} / \mathrm{D}$ of the extruder was $40 \mathrm{~mm}$ and the screw diameter was $16 \mathrm{~mm}$. The process was carried out at a cylinder temperature of $160-195{ }^{\circ} \mathrm{C}$. The cooled strands were then ground into pellets and dried. In the second step, the composite granules were injection molded at $200{ }^{\circ} \mathrm{C}$. This process resulted in shaped samples according to ASTM specifications for tensile and impact testing. 


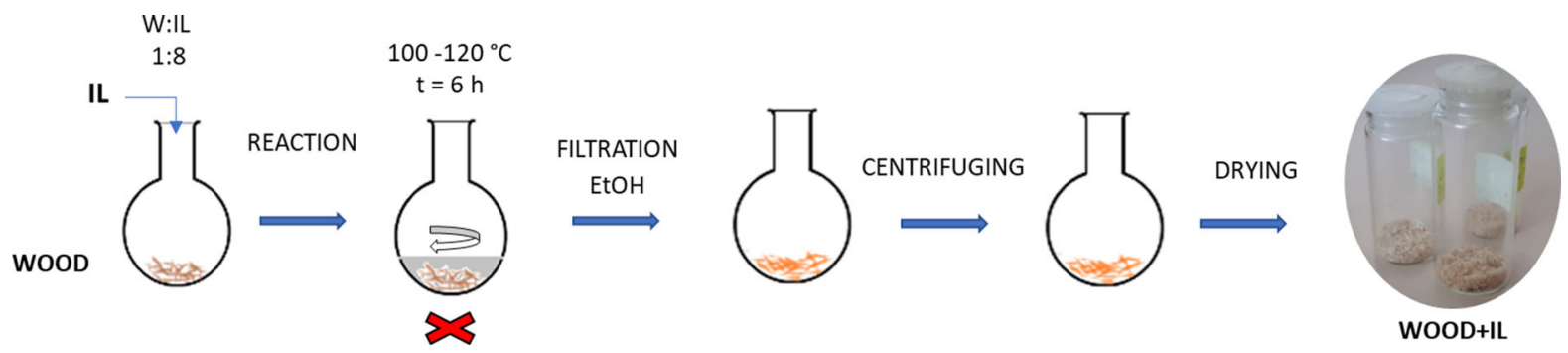

Fig. 2 The scheme of wood modification with novel ionic liquids

\section{Physicochemical characteristics of modified wood and composites}

NMR spectroscopy

To confirm the chemical structure and to investigate the purity of the newly synthesized ionic liquids, ${ }^{1} \mathrm{HNMR}$ and ${ }^{13} \mathrm{CNMR}$ analyses were performed. Nuclear magnetic resonance spectra were recorded using a Brucker spectrometer at $400 \mathrm{MHz}$ for ${ }^{1} \mathrm{H}$ NMR and $100 \mathrm{MHz}$ for ${ }^{13} \mathrm{C}$ NMR. Tetramethylsilane was used as an internal standard.

The results of NMR measurements are as follows:

$\mathrm{N}$-dodecyl-N-carboxymethyl-N,N-dimethylammonium bis(trifluoromethylsulfonyl)imide IL1: ${ }^{1} \mathrm{H}$ NMR (400 MHz, DMSO- $\left.d_{6}\right) \delta$ [ppm]: 0.85-0.88 $(\mathrm{t}, 3 \mathrm{H} J=6.8 \mathrm{MHz}) ; 1.26(\mathrm{~s}, 20 \mathrm{H}) ; 1.60-1.61(\mathrm{t}$; $\mathrm{J}=2.95,2 \mathrm{H}) ; 2.77(\mathrm{~s}, 6 \mathrm{H}) ; 3.00-3.04(\mathrm{~m} ; 2 \mathrm{H}) .{ }^{13} \mathrm{C}$ NMR (100 MHz, DMSO- $\left.d_{6}\right) \delta$ [ppm]: 13.8; 22.2; $23.83,25.89 ; 28.58 ; 28.87 ; 28.89 ; 28.94 ; 29.06$; $29.17 ; 31.45 ; 42.15 ; 56.84 ; 114.8 ; 118.0 ; 121.2$; $124.4 ; 167.12$.

$\mathrm{N}$-tetradecyl-N-carboxymethyl-N,N-dimethylammonium bis(trifluoromethylsulfonyl)imide IL2: ${ }^{1} \mathrm{H}$ NMR (400 MHz, DMSO- $d_{6}$ ) $\delta$ [ppm]: 0.77-0.8 (t, $3 \mathrm{H} J=6.85 \mathrm{MHz}$ ); $1.17(\mathrm{~s}, 24 \mathrm{H}) ; 1.51-1.54(\mathrm{~m}$; $2 \mathrm{H}) ; 2.77(\mathrm{~s}, 6 \mathrm{H}) ; 3.00-3.04(\mathrm{~m} ; 2 \mathrm{H})$.

${ }^{13} \mathrm{C}$ NMR (100 MHz, DMSO- $\left.d_{6}\right) \delta[\mathrm{ppm}]: 13.85$; 21,$89 ; 22.19 ; 23.78,25.87 ; 25.90 ; 28.59 ; 28.85$; $28.92 ; 29.06 ; 29.15 ; 29.19 ; 31.42 ; 42.09 ; 56.72$; $114.76 ; 117.96 ; 121.16 ; 124.36 ; 166.67$.

1-carboxymethyl-3-tetradecylimidazolium bis(trifluoromethylsulfonyl)imide $\quad$ IL3: $\quad{ }^{1} \mathrm{H} \quad$ NMR (400 MHz, DMSO- $\left.d_{6}\right) \delta$ [ppm]: 0.84-0.87 (t, 3H $J=6.8 \mathrm{MHz}) ; 1.24(\mathrm{~s}, 22 \mathrm{H}) ; 1.77-1.80(\mathrm{t}, 2 \mathrm{H}$ $J=7 \mathrm{MHz}) ; \quad 4.19-4.23 \quad(\mathrm{t}, \quad 2 \mathrm{H} \quad J=7.2 \mathrm{MHz})$; 7.71-7.72 (t, $1 \mathrm{H} J=1.75 \mathrm{MHz}) ; 7.77-7.78(\mathrm{t}, 1 \mathrm{H}$ $J=1.75 \mathrm{MHz}) ; 9.15$ (s, 1H). ${ }^{13} \mathrm{C}$ NMR $(100 \mathrm{MHz}$,
DMSO- $\left.d_{6}\right) \delta[\mathrm{ppm}]: 13.92 ; 22.14 ; 25.49 ; 25.74$; $28.4 ; 28.45 ; 28.77 ; 28.89 ; 29.0 ; 29.08 ; 29.11 ; 29.12$; $29.44 ; 31.35 ; 48.86 ; 50.42 ; 117.9 ; 121.11 ; 121.73$; $123.89 ; 137.02 ; 168.09$.

1-carboxymethyl-3-dodecylimidazolium bis(trifluoromethylsulfonyl)imide IL4: ${ }^{1} \mathrm{H}$ NMR (400 MHz, DMSO- $\left.d_{6}\right) \quad \delta \quad[\mathrm{ppm}]: \quad 0.84-0.88 \quad(\mathrm{t}, \quad 3 \mathrm{H}$ $J=6.85 \mathrm{MHz}) ; 1.25$ (s, 18H); 1.79 (m, 2H); $4.20-4.23$ (t, $2 \mathrm{H} J=7.2 \mathrm{MHz}) ; 7.71-7.72(\mathrm{t}, 1 \mathrm{H}$ $J=1.75 \mathrm{MHz}) ; 7.77-7.78(\mathrm{t}, 1 \mathrm{H} J=1.75 \mathrm{MHz})$; 9.14-9.15 (t, $1 \mathrm{H} \quad J=1.4 \mathrm{MHz}) .{ }^{13} \mathrm{C} \quad \mathrm{NMR}$ $\left(100 \mathrm{MHz}, \mathrm{DMSO}-d_{6}\right) \delta$ [ppm]: 13.90; 22.12; $25.48 ; 28.38 ; 28.76 ; 28.87 ; 28.98 ; 29.05 ; 29.43$; $31.33 ; 48.88 ; 50.3 ; 114.7 ; 117.9 ; 121.11 ; 121.76$; $123.89 ; 124.3 ; 137.04 ; 168.13$.

X-ray diffraction

The supermolecular structure of the obtained modified and raw wood samples were analyzed by X-ray diffraction (XRD). CuK $\alpha$ radiation was applied at an operating voltage of $30 \mathrm{kV}$ and an operating current of $25 \mathrm{~mA}$. The results were recorded as plots of reflection intensity as a function of diffraction angle $2 \Theta$, ranging from 5 to $30^{\circ}$ with step of $0.04^{\circ} / 3 \mathrm{~s}$. The method of Hindeleh (Hindeleh and Johnson 1971) corrected by Rabiej (Rabiej 1991) was used to perform deconvolution of the peaks. After separation of the X-ray diffraction lines, the degree of crystallinity $(\mathrm{Xc})$ of the wood was calculated for all samples by comparing the areas under the crystalline peaks and under the amorphous curve.

Additionally, diffractometric studies of the composite samples were conducted to characterize the polymorphic variations of the polymer matrix. 


\section{FTIR spectrometry}

Changes in chemical composition and structure of unmodified wood and samples after chemical modification with ionic liquids were determined by FTIR analysis. For this purpose, wood samples in the ratio of $1 / 200 \mathrm{mg}$ were mixed with $\mathrm{KBr}$ (Sigma-Aldrich, Germany). FTIR spectra were recorded using a Nicolet iS5 Infinity spectrophotometer (Thermo Fisher Scientific) with a Fourier transform in the wavelength range of 500-4000 cm-1 at a resolution of $4 \mathrm{~cm}-1$, recording 16 scans.

\section{Differential scanning calorimetry DSC}

DSC thermal analysis of wood-PP composites was carried out using a Netzsch DSC 200 calorimeter. Measurements were made in an inert gas (nitrogen) environment under dynamic conditions. At the first step, the samples were heated from $40{ }^{\circ} \mathrm{C}$ to $200{ }^{\circ} \mathrm{C}$ (heating rate $10{ }^{\circ} \mathrm{C} / \mathrm{min}$ ) and held at this temperature for $3 \mathrm{~min}$ to eliminate their thermal history. Then samples were cooled to $40{ }^{\circ} \mathrm{C}$ at a cooling rate of $5{ }^{\circ} \mathrm{C} /$ $\mathrm{min}$. This cycle was repeated twice and only the data recorded in the second round were used for calculations. The obtained results allowed to determine the characteristic temperatures of the material: crystallization temperature (Tc) and melting temperature (Tm), which were defined as the highest temperature of exothermic and endothermic peaks, respectively. The degree of crystallinity of the composites (Xc) was calculated from Eq. 1.

$\mathrm{Xc}=\left(\frac{\Delta \mathrm{Hm}}{\Delta \mathrm{Hm}^{0} \times\left(1-\frac{\% \mathrm{Wt} \text { filler }}{100}\right)}\right) \times 100$

where: $\Delta \mathrm{Hm}$ is the enthalpy of melting (from the second heating cycle), $\Delta \mathrm{Hm}^{\circ}$ is the enthalpy of melting of $100 \%$ crystalline polymer matrix (209.0 J/g for PP), and \% wt filler is the percentage of filler.

Furthermore, based on the dependence of the degree of phase conversion $(\alpha)$ as a function of crystallization time (Eq. 2), the half crystallization time $\left(\mathrm{t}_{0.5}\right)$ was determined, which is defined as the time at which $50 \%$ conversion of the amorphous to crystalline phase occurred.
$\alpha=\frac{\int_{0}^{t}\left(\frac{\mathrm{dH}}{\mathrm{dt}}\right) \times \mathrm{dt}}{\int_{0}^{1}\left(\frac{\mathrm{dH}}{\mathrm{dt}}\right) \times d t}$

Hot stage optical microscopy

Changes in the crystallization process of PP in the presence of chemically modified lignocellulosic fillers compared to composites filled with raw wood were analyzed using a Labophot-2 polarized optical microscope (Nikon) connected to a Panasonic CCD camera and equipped with a Linkam TP93 hot-stage device. During the measurement, composite samples were initially heated to $200{ }^{\circ} \mathrm{C}$ at a rate of $40{ }^{\circ} \mathrm{C} / \mathrm{min}$ and held at this temperature for $3 \mathrm{~min}$ to eliminate their thermal history. The samples were then cooled at a rate of $20^{\circ} \mathrm{C} / \mathrm{min}$ to $136{ }^{\circ} \mathrm{C}$, at which the isothermal crystallization process occurred. The nucleation activity of the modified lignocellulosic fillers in the PP matrix was investigated by observing the formation of transcrystalline structures.

Mechanical testing of composite materials

The tensile properties of WPCs were measured using a Zwick Z020 universal testing machine (Zwick/Roell). The measurements were performed according to PN EN ISO 527-3: 2019-01. The specimens were statically tensile with a load cell capacity of $20 \mathrm{kN}$ at a speed of $5 \mathrm{~mm} / \mathrm{min}$. The basic strength parameters of the composites were determined: Young's modulus (YM), stress at break (TS) and elongation at break (EB). According to ISO 179, Charpy notched impact tests were performed on specimens using a Zwick 5102 machine.

\section{Results}

Characterization of wood after modification with ionic liquids

\section{$X R D$}

Changes in the supermolecular structure of wood caused by chemical modification were analyzed using wide angle X-ray diffraction (XRD). The recorded 
diffraction patterns for unmodified and modified fillers are shown in Fig. 3.

$\mathrm{X}$-ray analysis showed significant changes in the structure of lignocellulosic fillers. The diffraction patterns showed characteristic diffraction maxima at the angles $2 \odot \approx 15^{\circ}, 17^{\circ}$ and $22.7^{\circ}$ clearly indicating the polymorphic variety of cellulose I. These peaks belong to the (110), (110) and (200) lattice planes, respectively (French 2014). Importantly, the modification of wood with ionic liquids did not result in conversion of the polymorphic form into cellulose II. Furthermore, it can be noted that the intensity of maxima showed a large variation, which may indicate changes in the content of the crystallinity of individual wood fillers. It was found that the intensity of the maxima from wood modified with ionic liquids was decreased compared to unmodified wood. Based on the obtained diffractograms, the content of the
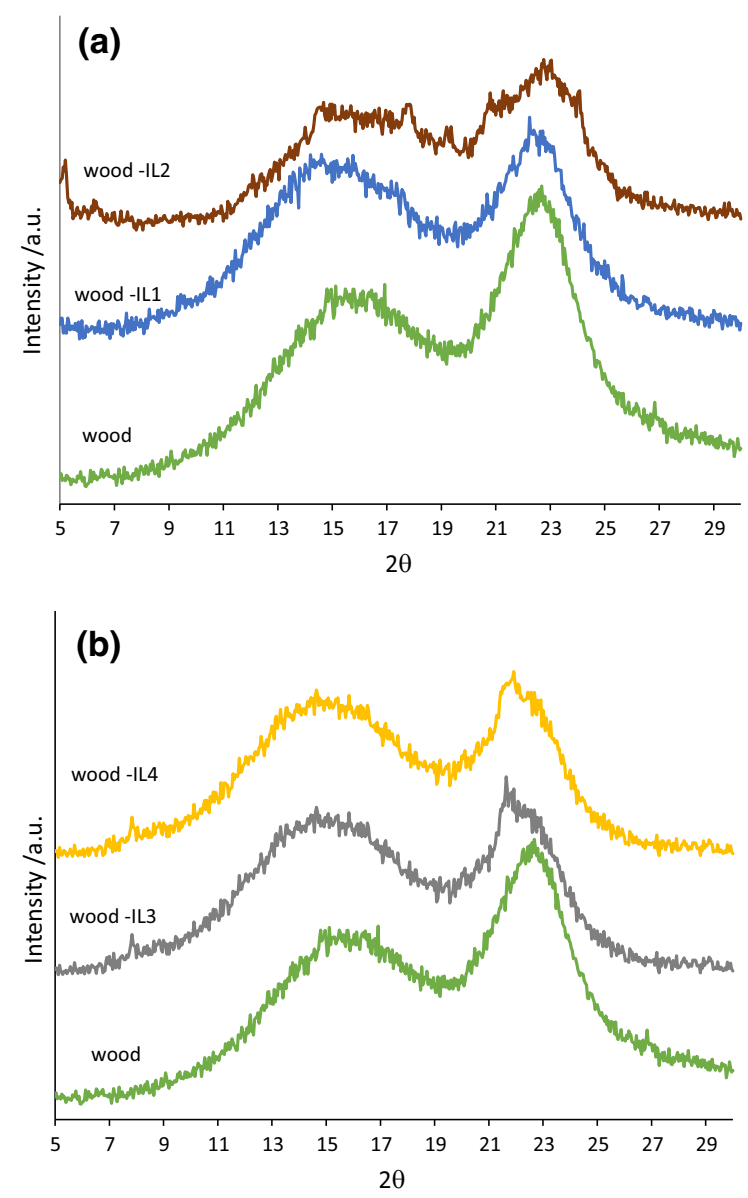

Fig. 3 X-ray diffraction patterns of unmodified wood and wood modified with ionic liquids $\mathbf{a}$ ammonium $\mathbf{b}$ imidazolium crystalline phase $(\mathrm{Xc})$ in the filler samples was determined (Table 2).

The use of all ionic liquids in the modification of fillers resulted in reduction of the crystalline phase content. The decrease in Xc is particularly noticeable in the case of the use of ammonium salts, where the degree of crystallinity was obtained at the level of $30-38 \%$. The wood modified with imidazolium salts was characterized by much higher crystallinity values (appx. 42-43\%) compared to the liquid with ammonium cation. X-ray studies did not show any significant effect of alkyl chain length on the content of crystalline phase of the modified wood fillers. The decrease in the content of crystalline phase can be explained by the changes taking place at the level of the intermolecular interactions of cellulose. During modification, ionic liquids penetrate the structure of polysaccharides and, as a result of the reaction of hydroxyl groups with the carboxyl group of the cation, break intermolecular and intramolecular hydrogen bonds, especially in the crystalline region of cellulose. The ordered structure is disturbed as evidenced by a decrease in the value of the Xc parameter. Similar relationships were noted and described in the previous work, in which dodecyldimethylammonium bis(trifluoromethylsulfonyl)imide was used to modify the wood (Borysiak et al. 2018). It is worth noting, however, that in the case of the innovative modifiers that are the subject of this study, a much greater reduction in the value of the degree of crystallinity was obtained, which may be the result of the formation of covalent bonds between the wood and the modifier.

\section{FTIR spectroscopy}

Fourier transform infrared spectroscopy (FTIR) was performed to evaluate the effectiveness of the chemical modifications of pine wood. Figure 4 shows FTIR spectra of pine wood before and after the chemical reaction with ionic liquids.

Table 2 The crystallinity degree $(\mathrm{Xc})$ of lignocellulosic fillers

\begin{tabular}{ll}
\hline & Xc [\%] \\
\hline wood & 52 \\
wood-IL1 & 38 \\
wood-IL2 & 30 \\
wood-IL3 & 43 \\
wood-IL4 & 42 \\
\hline
\end{tabular}


The obtained spectra revealed chemical changes in the wood and allowed to confirm the effectiveness of the chemical modification process with ionic liquids. Most of the characteristic frequencies were in the range from 4000 to $400 \mathrm{~cm}-1$. In the case of unmodified pine wood, characteristic strong bands were observed, among which we can distinguish those with a wave number of about $3430 \mathrm{~cm}-1$ and $2900 \mathrm{~cm}-1$, originating from $\mathrm{O}-\mathrm{H}$ stretching vibrations and $\mathrm{C}-\mathrm{H}$ stretching vibrations, respectively. In addition, at the wave number of about $1740 \mathrm{~cm}-1$, a band of medium intensity coming from $\mathrm{C}=\mathrm{O}$ stretching vibrations was recorded (Pandey 1999). It is also worth emphasizing that higher intensity of this band was observed for wood samples modified with imidazolium ionic liquids, which may indicate a higher efficiency of this type of modification compared to modification with ammonium liquids. For the filler samples subjected to chemical modifications, the occurrence of all bands characteristic for raw wood was observed. At the same time, at the wave number of about $1690-1760 \mathrm{~cm}-1$ and about $1100 \mathrm{~cm}-1$, an increase in the intensity of the bands was recorded, which come from the $\mathrm{C}=\mathrm{O}$ and $\mathrm{C}-\mathrm{O}$ stretching vibrations of the ester group, respectively. The obtained results are consistent with previous reports (Abushammala et al. 2017), in which the appearance of the same bands was observed in cellulose and lignin samples subjected to acetylation reaction as a modifier using 1-acetylimidazole.The band at a wavelength of about $1700 \mathrm{~cm}-1$ resulting from vibrations of the ester bond after cellulose acetylation reaction was also noted in the work of $\mathrm{Zhu}$ et al. (Zhu et al. 2020). Thus, it can be concluded that the appearance of these bands proves the effectiveness of the reaction of the carboxyl group of the ionic liquid with the hydroxyl groups of wood.

Moreover, on the obtained spectra at the wavelength of $2960 \mathrm{~cm}-1$, high-intensity bands were observed, related to the occurrence of $\mathrm{C}-\mathrm{H}$ stretching vibrations derived from the alkyl substituent at the cation of the ionic liquids used. For the wave number $1350 \mathrm{~cm}-1$ and $1195 \mathrm{~cm}-1$ was recorded as a band of medium intensity derived from stretching vibration $\mathrm{S}=\mathrm{O}$ for sulfones. Also, the bands at about $1230 \mathrm{~cm}-1$ and $1060 \mathrm{~cm}-1$, which come from $\mathrm{C}-\mathrm{N}$ stretching vibrations, and about $1080 \mathrm{~cm}-1$ coming from $\mathrm{C}-\mathrm{F}$ stretching vibrations, confirm that the chemical modification with the applied ionic liquids was effective (Ones 1978; Borysiak et al. 2018). Figure 5 proposes the mechanism of wood reaction with the ionic liquids used.

Physicochemical characterization of WPCs

\section{Differential scanning calorimetry DSC}

The thermal analysis of the composites by differential scanning calorimetry (DSC) was carried out to study the effect of chemical modification of lignocellulosic fillers on the phase transformations in the PP matrix. Figures 6 and 7 show the curves of exo- and endothermic transformations.

The analysis of the obtained data has shown that chemical modification of wood does not cause significant changes in the course of endothermic transformations of polypropylene matrix (Fig. 6). The obtained curves had a similar course, and the maxima visible in the thermograms were characterized by a similar position. On the other hand, significant changes were noted in the case of exothermic transformation (Fig. 7). It was noticed that the introduction of lignocellulosic fillers into the polymer matrix causes a shift of the peak maxima towards higher temperatures. In addition, visible differences in the width of the peaks were observed, which may indicate a possible differentiation in the course of the matrix crystallization process. On the basis of the obtained curves, the melting point (Tm) and crystallization (Tc) values were determined for pure polypropylene and $\mathrm{PP} /$ wood composites. The results are summarized in Table 3.

The obtained melting point values for all tested systems were comparable with the melting point of pure polypropylene and ranged between 162.6 and $164.5^{\circ} \mathrm{C}$. Similar correlations have been observed in many previous works on wood modification. e.g. in the work of Ichazo, who used in his study silane compounds to treat this materials (Ichazo et al. 2001). It can therefore be assumed that changes caused by the chemical interaction of reagents with wood, including ionic liquids, do not have a significant impact on the course of endothermic changes.

The DSC results of the exothermic phase transition of the composite systems studied allowed to find the relationship between the polypropylene crystallization temperature and the type of filler used. The Tc of unfilled PP was $114.2{ }^{\circ} \mathrm{C}$. The introduction of unmodified wood into the matrix increased this value to 

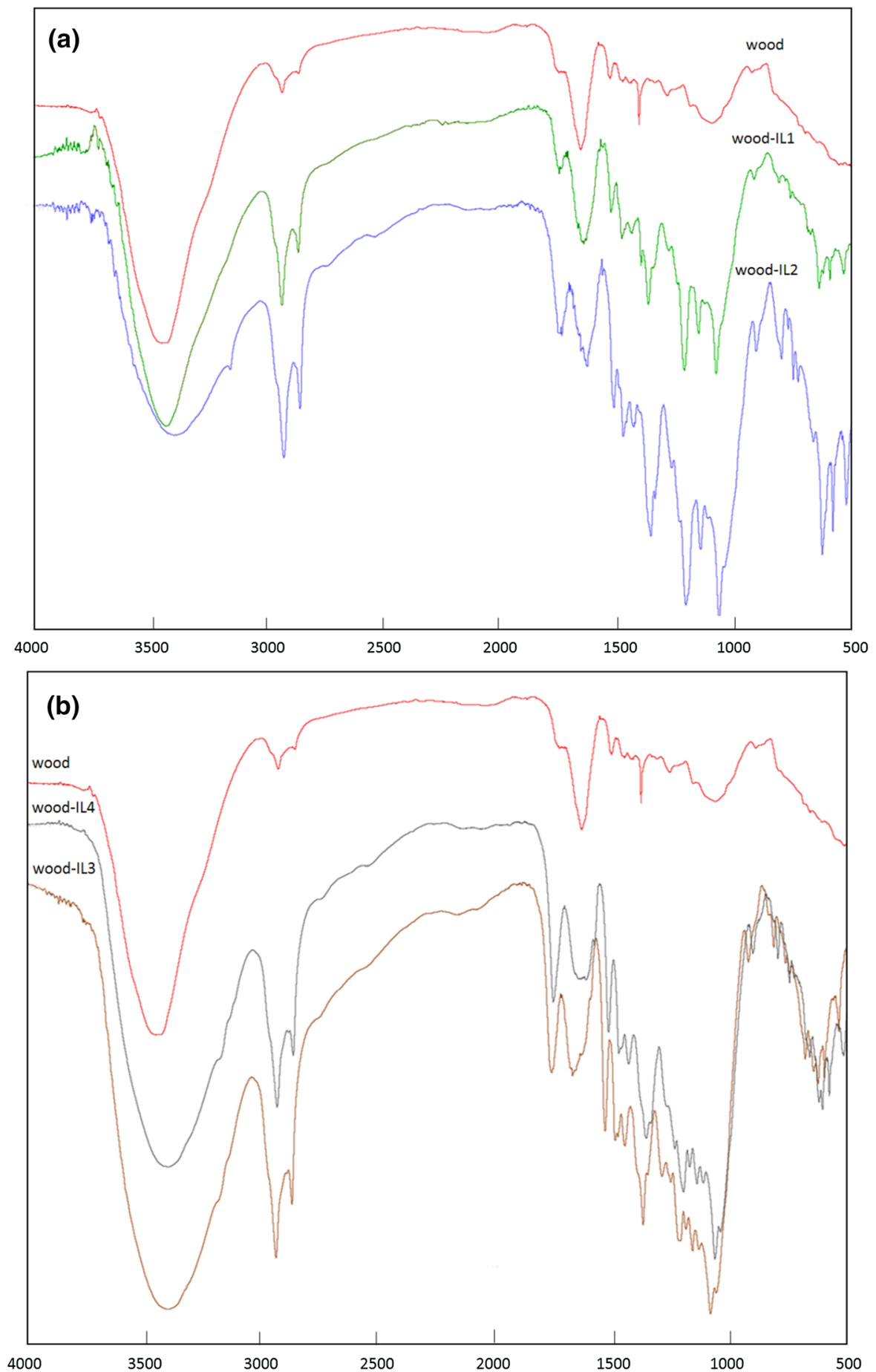

Fig. 4 FTIR spectra of wood modified with IL: a ammonium, b imidazolium

$115.4{ }^{\circ} \mathrm{C}$. Similar results were obtained for composite samples containing wood modified with ammonium ionic liquids (IL1 and IL2), for which, regardless of the structure of the alkyl substituent, the obtained values were similar to raw wood $\left(115\right.$ and $115.5^{\circ} \mathrm{C}$ respectively). Interestingly, the introduction of fillers 


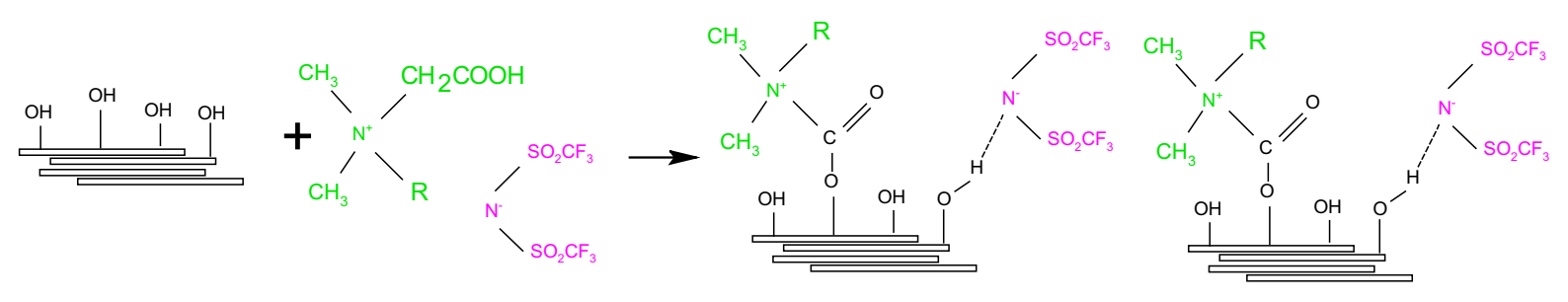

Fig. 5 Proposed mechanism of reaction wood with ionic liquids

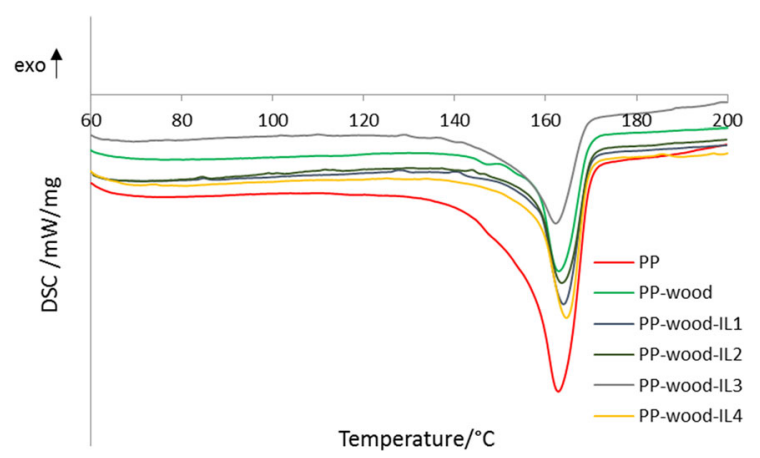

Fig. 6 DSC thermograms of the melting process for iPP and composite materials

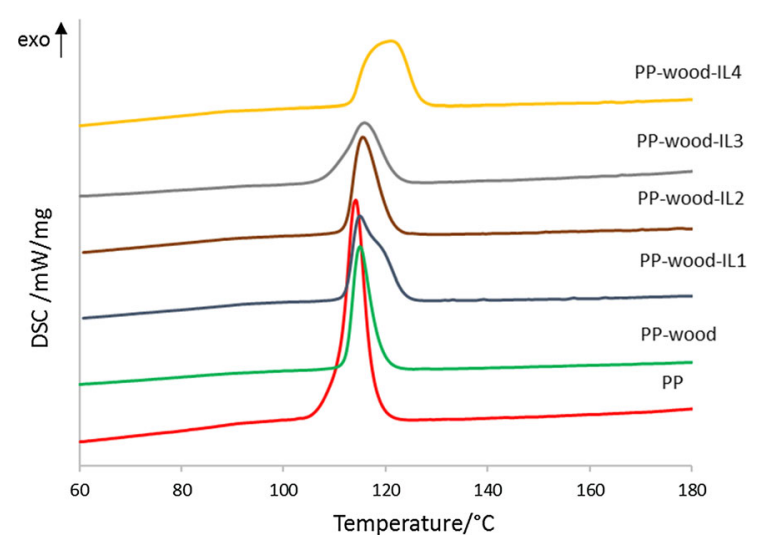

Fig. 7 DSC thermograms of the crystallization process for iPP and composite materials

treated with imidazolium ionic liquids resulted in the greatest increase in the Tc value, even by more than $6{ }^{\circ} \mathrm{C}$, but only for the PP-wood-IL4 sample, where the alkyl substituent of the ionic liquid was shorter (C12). For wood modified with an imidazolium ionic liquid with a longer substituent, the Tc values were comparable for wood modified with ammonium liquids.

The obtained dependencies clearly show that the value of the crystallization temperature of composite samples with wood modified with ionic liquids strictly
Table 3 The melting (Tm) and crystallization (Tc) temperatures for all tested systems

\begin{tabular}{lll}
\hline & $\mathrm{Tm}\left[{ }^{\circ} \mathrm{C}\right]$ & $\mathrm{Tc}\left[{ }^{\circ} \mathrm{C}\right]$ \\
\hline PP & 162.7 & 114.2 \\
PP-wood & 163.0 & 115.4 \\
PP-wood-IL1 & 163.1 & 115.0 \\
PP-wood-IL2 & 162.6 & 115.5 \\
PP-wood-IL3 & 163.5 & 115.7 \\
PP-wood-IL4 & 164.5 & 120.8 \\
\hline
\end{tabular}

depends on the type of the cation used (ammonium, imidazolium) and its spatial structure, i.e., the length of the alkyl substituents. It should also be noted that for all the samples containing the chemically modified filler, the Tc values were higher than those for the unfilled polymer matrix. These results prove the high nucleating capacity of the fillers, and the wood-IL4 filler turned out to be the most effective in the process of nucleation of the polypropylene matrix. It is also worth adding that so far carrying out many chemical modifications of wood with modifiers such as: acid anhydrides (Quillin et al. 1993), carbonyl diimidazoles (Lenes and Gregersen 2006), ionic liquids (Borysiak et al. 2018) has been responsible for the reduction of nucleating activity compared to raw wood.

In the next stage, in order to confirm the influence of chemical modification of wood on the nucleation capacity of the obtained filler, the degree of conversion of the amorphous to crystalline phase and the crystallization half-time $\left(\mathrm{t}_{0.5}\right)$ were determined. The results are shown in Fig. 8 and Table 4.

The introduction of lignocellulosic filler into the polymer matrix significantly influenced the course and kinetics of the crystallization process. Significant changes in the shape of phase conversion curves and 
in the values of half-time of crystallization were observed. For all composite samples, an increase in the degree of phase conversion and a reduction in the halftime of crystallization compared to unfilled PP can be noticed. It can also be observed that the composites with wood modified with ammonium ionic liquids were characterized by comparable values of $\mathrm{t}_{0.5}$ to the systems with unmodified wood (appx. 2.4-2.5 min). In the case of composites containing wood modified with imidazolium liquids, a shortening of half-times of crystallization was noted, which is particularly noticeable for the system with wood treated with a modifier with a shorter alkyl substituent $\left(\mathrm{t}_{0.5}=2.2 \mathrm{~min}\right)$. The differences in the values of the crystallization parameters obtained by the samples modified with ammonium and imidazolium liquids may be caused by the different nature of their interactions both with the wood surface and with PP chains. During modification, ionic liquids are built into the structure of wood, which in consequence may hinder migration of polymer chains, causing spatial hindrance around the lignocellulosic filler. The comparison of the effect of the alkyl chain length shows that the course of the nucleation process is easier in the case of a liquidmodified wood with a shorter alkyl substituent.

Chemical modification of wood with ionic liquids containing functional groups capable of forming permanent covalent bonds is a new field of research and there are no reports in the literature devoted to the analysis of the influence of this modifying factor on the physicochemical properties of the filler, including its nucleation activity. Previous studies on the chemical treatment of wood, in contrast to those obtained in this paper, described a decrease in the nucleation capacity of chemically modified lignocellulosic fillers

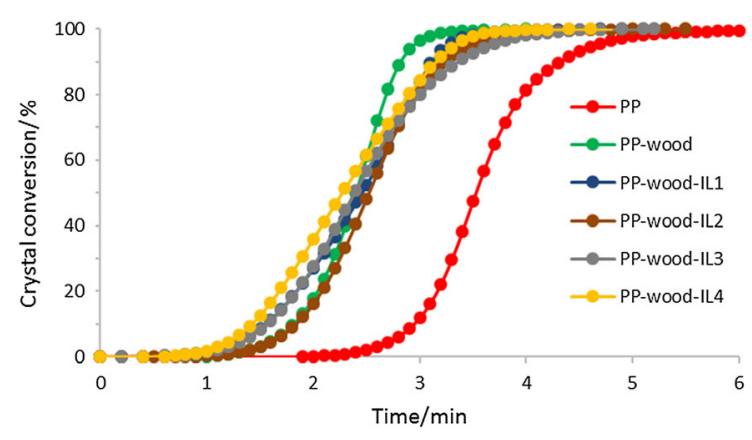

Fig. 8 The crystal conversion of PP matrix and composite materials with wood modified
Table 4 The crystallization half-times $\left(\mathrm{t}_{0.5}\right)$ for all tested systems

\begin{tabular}{ll}
\hline & $\left(\mathrm{t}_{0.5}\right)[\mathrm{min}]$ \\
\hline PP & 3.5 \\
PP-wood & 2.4 \\
PP-wood-IL1 & 2.4 \\
PP-wood-IL2 & 2.5 \\
PP-wood-IL3 & 2.3 \\
PP-wood-IL4 & 2.2 \\
\hline
\end{tabular}

(Amash and Zugenmaier 2000; Arbelaiz et al. 2006; Yang et al. 2010; Borysiak 2012; Johari et al. 2016). The increase in the surface activity of wood modified with imidazolium ionic liquid containing carboxyl groups obtained in this study is extremely important, although it should be emphasized that the mechanism of the heterogeneous nucleation process is a complicated process, dependent on many factors and has not been fully understood yet.

In order to confirm the obtained results concerning the improvement of the nucleation activity of wood subjected to chemical modification, in the next stage, polarized light microscopy studies were performed with a heating attachment.

\section{Hot stage polarized light microscope}

Figure 9 shows the process of isothermal crystallization of polypropylene in the presence of various lignocellulosic fillers at $136{ }^{\circ} \mathrm{C}$.

The obtained microscopic images show a large variation in the course of isothermal crystallization of polypropylene, which shows how much the process is influenced by the type of filler used. In all samples, the formation of transcrystalline structures of the polypropylene matrix was observed, but with different effectiveness. In each system, the nucleation took place preferentially along the wood filler, although in the case of composites containing wood modified with ammonium liquids (Fig. 9b and c), simultaneous formation of a fine-spherulite structure in the "mass" of the polymer and the formation of transcrystalline structures near the wood surface with a very low density were observed. A completely different course of crystallization occurs in systems with wood modified with imidazolium compounds (Fig. 9d and e). For these systems, mainly the formation of transcrystalline structures was observed, while few spherulites appear in the "mass" of the polymer. However, it can be seen 

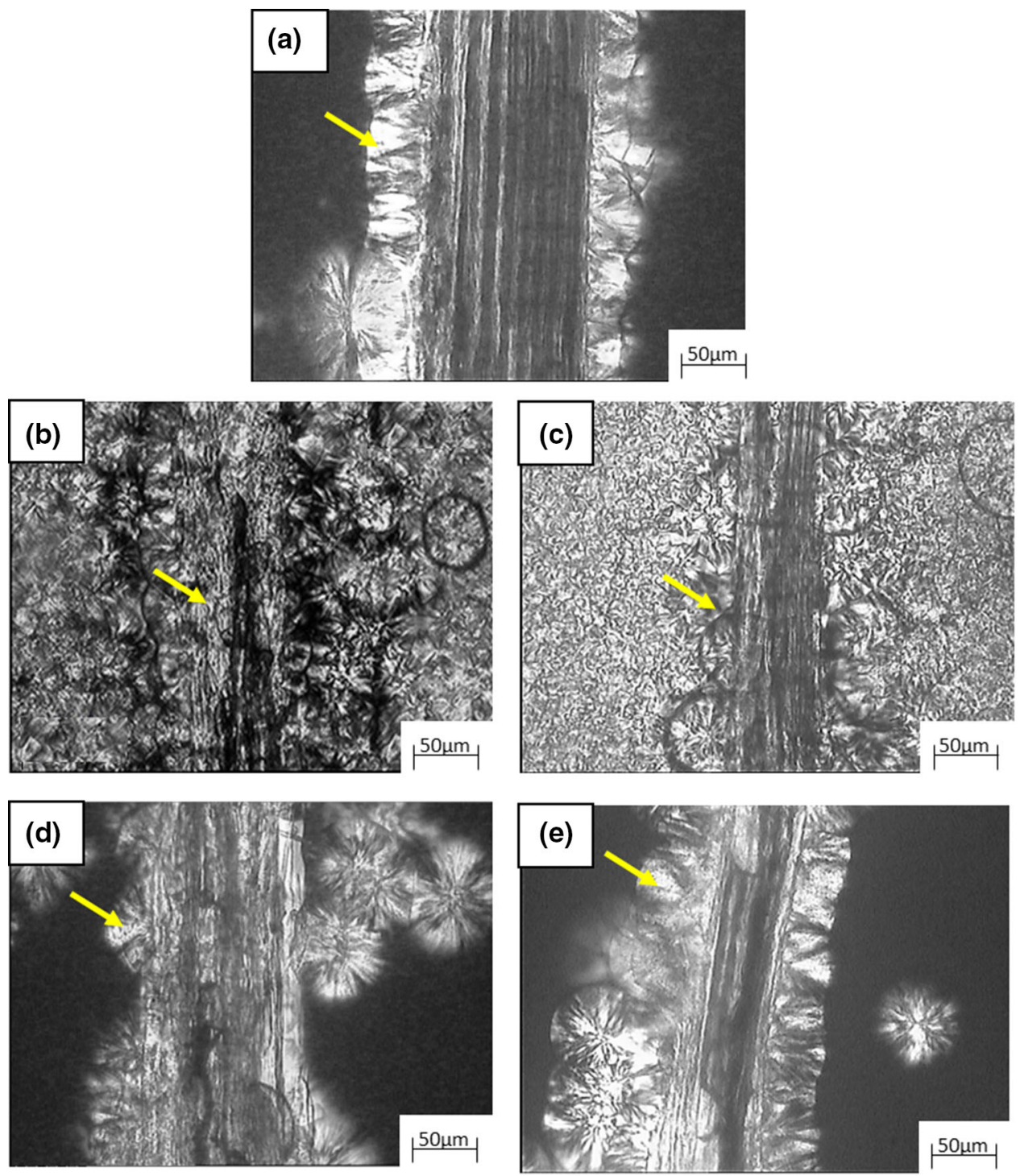

Fig. 9 PLM pictures of polypropylene recorded in the presence of: a unmodified wood, $\mathbf{b}$ wood-IL1, $\mathbf{c}$ wood-IL2, d wood-IL3, e woodIL4. The yellow arrow marks the appearing TLC layer

that the effectiveness of the formation of structures at the interface significantly depends on the structure of the imidazolium cation. The use of a modifier with a shorter alkyl substituent (Fig. 9e) is responsible for obtaining a very high nucleation activity of the wood surface, which is manifested by a high density of the formed centers of nuclei. In the case of using an imidazolium liquid with a longer alkyl substituent $\mathrm{C} 14$ (Fig. 9d), the formation of TCL layers was also found, but with a much lower density It is also worth emphasizing that the on-line research of the crystallization process showed that the modification of wood with the use of ammonium ionic liquids and imidazolium liquids with a long aliphatic chain resulted in a reduction of the nucleation capacity of wood compared to the unmodified filler (Fig. 9a).

In the further part of the study, the average growth rate of spherulites was determined for all tested systems. The obtained results are summarized in Table 5.

The highest growth rate of the TLC layer was recorded for the PP-wood-IL4 system $(5 \mu \mathrm{m} / \mathrm{min})$, for 
which the highest efficiency of heterogeneous nucleation was observed. This value is higher than the growth rate of TCL for the system with unmodified wood $(4.5 \mu \mathrm{m} / \mathrm{min})$, which clearly confirms the increase in the nucleation activity of wood in the case of using the modifier in the form of an imidazolium liquid with a shorter alkyl substituent For composites containing wood modified with ammonium liquids, the lowest growth rate of TCL was obtained (appx. $2 \mu \mathrm{m} / \mathrm{min}$ ), which confirms that this type of modification is responsible for the reduction of nucleation activity. The use of wood modification with the use of imidazolium liquid with a longer alkyl substituent resulted in obtaining slightly higher TCL growth rates compared to ammonium modifying systems.

The literature reports to date indicate that there are many factors influencing the mechanism of the transcrystalline layer formation in the polymer matrix. These include, for example, the type and structure of the filler, the topography of its surface, and the cooling rate (Cai et al. 1997; Quan et al. 2005; Borysiak 2013b; Raka and Bogoeva-Gaceva 2017). It should also be emphasized that the previous studies mainly show that carrying out the chemical modification of lignocellulosic fillers with modifiers reduces the nucleating activity, which the authors often explain by removing impurities and other non-structural components of wood that can potentially be active nucleants.

In this study, it was shown that the selection of an appropriate modifier structure in the form of imidazolium ionic liquid may contribute to the increase of nucleating activity, which is extremely important in the context of obtaining good interfacial adhesion. Such an effect of improving nucleation activity may be the result of a better matching of the crystal structure of cellulose functionalized with an ionic liquid with a suitable structure of the imidazolium cation to the

Table 5 Growth Rate of TCL in WPCs

\begin{tabular}{ll}
\hline Samples & Growth rate of TLC $[\mu \mathrm{m} / \mathrm{min}]$ \\
\hline PP-wood & 4.5 \\
PP-wood-IL1 & 2.0 \\
PP-wood-IL2 & 2.1 \\
PP-wood-IL3 & 2.8 \\
PP-wood-IL4 & 5.0 \\
\hline
\end{tabular}

polypropylene chains. Considerations of the related epitaxy effect responsible for the formation of transcrystalline structures have been the subject of several papers (Borysiak 2010, 2013a).

In conclusion, microscopic studies have shown that designing an appropriate structure of the modifying agent for chemical wood treatment is an important criterion in obtaining fillers with good nucleation activity. The results of microscopic study are consistent with the DSC tests which show that the composites with wood modified with imidazolium ionic liquid with alkyl substituent $\mathrm{C} 12$ showed the highest nucleation activity, which is confirmed by the determined kinetic parameters of the nucleation and crystallization process of the polymer matrix in the presence of fillers.

The phenomenon of transcrystalline layer formation in the process of polypropylene crystallization in the presence of the filler is extremely important and particularly desirable, because its occurrence is directly connected with obtaining much better mechanical properties of the material in comparison with those in which this phenomenon does not occur. Therefore, mechanical tests were also performed (Sect. Mechanical testing) to confirm the application potential of the obtained composite materials.

\section{$X$-ray diffraction examination}

The XRD analysis was performed in order to determine the influence of the wood functionalization on the supermolecular structure of composite materials. The obtained diffraction curves are shown in Fig. 10.

On the diffractograms can be observed maxima indicating the presence of two polymorph variety of polypropylene. The $\alpha$-PP form was recorded at the diffraction angles $2 \Theta=14^{\circ}, 17^{\circ}, 18.5^{\circ}, 21^{\circ}$ and $22^{\circ}$, while the maximum related to the $\beta$-PP variety appeared at the deflection angles of $16.2^{\circ}$. By analyzing the obtained diffraction curves, the exact contents of the $\beta$-PP form in the tested systems were determined. The results are summarized in Table 6 .

The content of polymorphic beta variety in unfilled PP was 9\%. The composite materials were characterized by significantly higher contents of this structure. The highest results were recorded for the systems containing wood modified with imidazolium ionic liquid IL3 and IL4 (34 and 39\%). The introduction of fillers treated with ammonium ionic liquids to the 
Fig. 10 X-ray diffraction pattern of PP and its composites with unmodified and modified wood

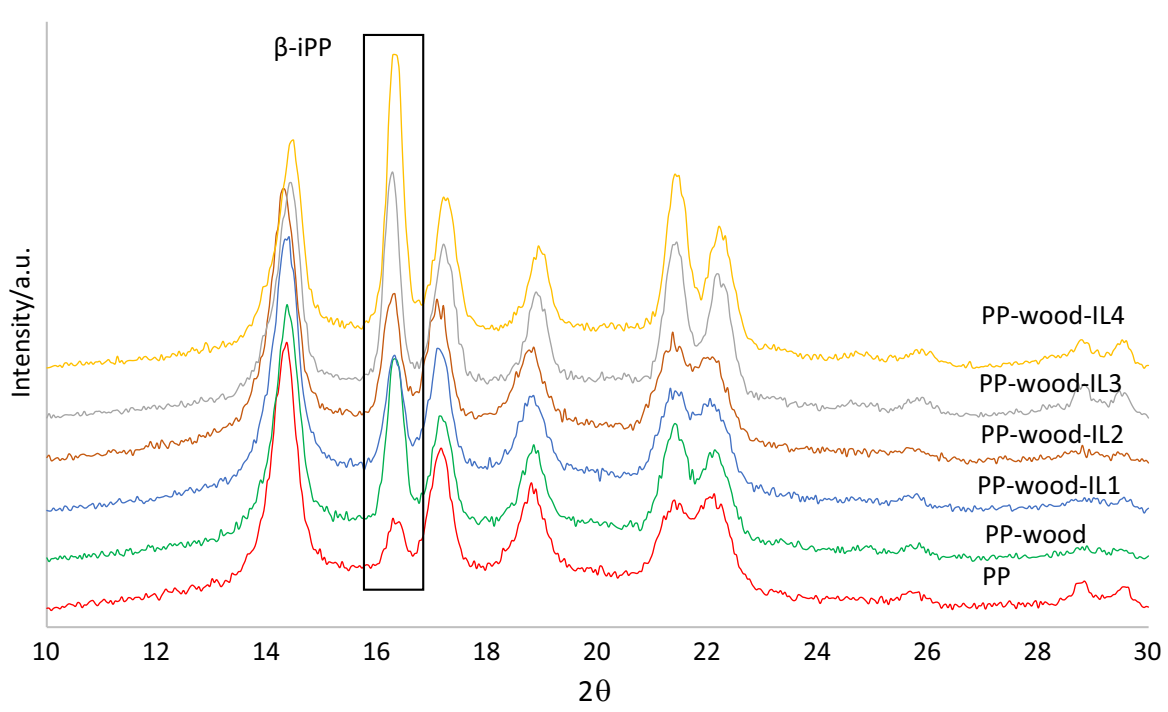

matrix resulted in a significant reduction in the content of the $\beta$-PP form, even below the value for raw wood, $20 \%$ for PP-wood-IL1 and 23\% for PP-wood-IL2.

The formation of the hexagonal $\beta$ structure of isotactic polypropylene in the tested systems can be explained by the action of shear forces occurring during the processing process. Their effect is enhanced when filler particles are introduced into the highmolecular polymer matrix. It is related to the appearance of additional stresses between the components. It should be noted that the shaping of the $\beta$-PP polymorph is also influenced by the course of the crystallization process of the polymer matrix. It is well known that this process is characterized by the occurrence of a polymorphic transition from the metastable $\beta$-phase to the stable $\alpha$-phase (Varga 1992b; Lotz 1998; Mollova et al. 2013). Similar relationships were observed in previous work, where the improvement of interfacial interactions was obtained in the modification process with hybrid

Table 6 The content of $\beta$ phase in WPCs

\begin{tabular}{ll}
\hline & $\mathrm{k} \beta[\%]$ \\
\hline PP & 9 \\
PP-wood & 25 \\
PP-wood-IL1 & 20 \\
PP-wood-IL2 & 23 \\
PP-wood-IL3 & 34 \\
PP-wood-IL4 & 39 \\
\hline
\end{tabular}

propylene/silane compounds (Odalanowska et al. 2021).

The obtained results correlate very well with the previously determined crystallization parameters. The highest efficiency of $\beta$-PP formation was observed for the PP-wood-IL4 system for which the highest Tc values and the highest TCL layer formation rate were recorded. The decrease in the nucleation activity of fillers modified with ammonium ionic liquids, observed in the results of DSC tests and in microscopy, was consequently associated with obtaining the lowest content of the hexagonal phase. The obtained results showed that it is possible to precisely design the structure of an ionic liquid capable of modifying the lignocellulosic filler, the introduction of which into the matrix will result in obtaining the assumed crystallization parameters and, consequently, specific functional properties of the material.

\section{Mechanical testing}

Mechanical tests were carried out in order to evaluate the effect of the applied novel method of filler modification on the strength characteristics of the obtained polymer composites. The results of strength at break, Young's modulus, elongation at break and impact toughness are summarized in Table 7.

It was noticed that all composite systems had better tensile strength properties compared to the unfilled material. The introduction of raw wood and wood modified with ammonium ionic liquids into the matrix 
resulted in an increase of this parameter by about $10 \%$. It can be seen that significantly higher values of stress at break were obtained when wood was modified with imidazolium ionic liquids. The composites with wood modified with imidazolium ionic liquids with shorter aliphatic substituents (PP-wood-IL4) showed tensile strengths of about $39 \mathrm{MPa}$. The conducted research also showed that the highest value of Young's modulus of elasticity $(2.51 \mathrm{GPa})$ was recorded for the system containing wood subjected to modification with an ionic liquid containing a cation with a shorter alkyl substituent. In the case of composites with wood modified with imidazolium IL with a longer aliphatic substituent, comparable values of modulus of elasticity were found in composites with unmodified wood. The use of wood modified with ammonium liquids resulted in composites with lower modulus values.

Very interesting results were obtained in the study of impact strength and elongation at break. All tested systems were characterized by lower values of these parameters in comparison to the matrix, which is a characteristic feature of the produced polymeric composite materials (Nuñez et al. 2003; Ndiaye et al. 2012; Michalska-Pozoga and Rydzkowski 2016). However, modification of the filler with the imidazolium ionic liquid with a shorter alkyl substituent resulted in a considerable variation. PP-woodIL4 composites were characterized by an increase in elongation at break (up to three times) and an increase in the impact toughness (appx. 50\%) compared to materials filled with raw wood. It should be added that the statistical analysis showed very similar values of standard deviations for all tested composite systems, which in the case of tensile strength results are approx. $1 \%$, and in the case of Young's modulus approx. $3-5 \%$. The situation is slightly different in the case of the results of elongation at break and impact strength. It was noticed that much lower values of standard deviations were obtained in the case of composites containing wood modified with ionic liquids, which amount to approx. 3-7\% (elongation at break) and $1-2 \%$ (for impact strength). In the case of composites with unmodified wood, these values are $16 \%$ and $5 \%$, respectively. The obtained results of the analysis prove the uniform dispersion of the modified filler in the matrix, which could not be obtained in the case of raw wood.

The obtained results clearly indicate that this system was characterized by the best interfacial adhesion, which perfectly correlates with the performed DSC and microscopic examinations. The composites with wood modified with the IL4 ionic liquid showed high nucleation activity, which confirmed the formation of transcrystalline structures at the interface of the filler polymer, which in turn resulted in obtaining very good strength properties. In addition, the achievement of high flexibility and impact strength can also be explained by the high content of the $\beta$-PP form, which, according to the literature, is characterized by much higher flexibility and impact strength than the $\alpha$ form (Varga 1992a; Borysiak et al. 2018). It is worth emphasizing, however, that the final properties of composite materials depend not only on the content of individual polymorphs of the polypropylene matrix, but also on such factors as: the degree of crystallinity of the cellulose filler or the topography of the filler surface. However, it is difficult to assess the direct impact of lowering the degree of crystallinity of cellulose fillers as a result of the chemical modifications carried out, because during the preparation of composite materials by means of extrusion and injection techniques, the

Table 7 Mechanical properties of PP and wood/PP composites

\begin{tabular}{lllcc}
\hline Composites & Tensile Strength [MPa] & $\begin{array}{l}\text { Young's Modulus } \\
{[\mathrm{GPa}]}\end{array}$ & $\begin{array}{c}\text { Elongation at break [\%] } \\
\text { Impact strength [kJ/m2] }\end{array}$ \\
\hline PP & $30.1 \pm 0.18$ & $1.32 \pm 0.12$ & $406 \pm 18.4$ & $54.1 \pm 0.58$ \\
PP-wood & $33.6 \pm 0.31$ & $2.34 \pm 0.11$ & $3.72 \pm 0.62$ & $21.7 \pm 1.08$ \\
PP-wood-IL1 & $32.9 \pm 0.41$ & $2.07 \pm 0.06$ & $7.1 \pm 0.32$ & $25.4 \pm 0.38$ \\
PP-wood-IL2 & $34.3 \pm 0.32$ & $2.04 \pm 0.08$ & $6.8 \pm 0.24$ & $26.1 \pm 0.47$ \\
PP-wood-IL3 & $36.4 \pm 0.28$ & $2.27 \pm 0.12$ & $4.6 \pm 0.35$ & $22.7 \pm 0.63$ \\
PP-wood-IL4 & $39.3 \pm 0.36$ & $2.51 \pm 0.11$ & $12.4 \pm 0.41$ & $32.1 \pm 0.41$ \\
\hline
\end{tabular}


shear forces responsible for the formation of individual polymorphs of the polymer matrix, which are characterized by different strength properties, will always be present.

The conducted mechanical tests allowed to unequivocally confirm the effectiveness of the modification in terms of hydrofibilization of the filler surface, which consequently significantly influenced the strength parameters of the obtained composite materials.

\section{Conclusions}

The paper presents the possibility of using newly synthesized ionic liquids containing reactive functional groups in the process of hydrophobization of the surface of lignocellulosic fillers and the influence of the modification on the physicochemical properties of WPCs was determined. High effectiveness of the reaction was confirmed by FTIR and XRD investigations of the modified fillers. In the FTIR spectra, an increase in the intensity of the bands was observed, which come from the $\mathrm{C}=\mathrm{O}$ and $\mathrm{C}-\mathrm{O}$-stretching vibrations of the ester group, respectively. Moreover, the appearance of bands characteristic for $\mathrm{S}=\mathrm{O}, \mathrm{C}-\mathrm{N}$ and $\mathrm{C}-\mathrm{F}$ bonds was recorded. Chemical modification also influenced the supermolecular structure of the filler and its nucleation activity in relation to the polymer matrix. The greatest changes were observed for the fillers modified with 1-carboxymethyl-3-dodecylimidazolium bis(trifluoromethylsulfonyl)imide (IL4). The composites containing this filler were characterized by the highest content of the hexagonal form of $\beta$-PP and significantly higher nucleation capacity compared to composites containing raw wood. The highest $\mathrm{Tc}$ values and the lowest $\mathrm{t} 0.5$ values were obtained for PP-wood-IL4 systems. Moreover, the PLM images showed the greatest efficiency in the formation of the highly desirable transcrystalline TLC layer. Modification of wood with ammonium ionic liquids (IL1, IL2) and imidazolium ionic liquid with a longer alkyl substituent (IL3) resulted in the lack of significant change in the nucleation capacity of the fillers in relation to the matrix, despite the increase in the beta phase content in composite systems.

Changes in the polymorphic structure of composites containing modified wood compared to systems with raw wood resulted in obtaining better strength properties of the composites. The obtained results indicate the high efficiency of the filler modification reactions in terms of their hydrophobization, and thus the improvement of interactions at the interphase level.

In summary, a relationship between the structure of the ionic liquid used for modification and the physicochemical properties of composites were found. It has been shown that it is possible to accurately design an ionic liquid containing a reactive functional group capable of interacting with the hydroxyl groups of cellulose molecules, which will result in obtaining composite materials with a predetermined supermolecular structure, high nucleation activity, and consequently decisive for the final strength properties. Moreover, it should be emphasized that the possibility of functionalisation of lignocellulosic material with the use of innovative ionic liquids was presented for the first time, without the need to use organic solvents or other modifiers.

Acknowledgments This work was supported by the Polish Ministry of Education and Science.

\section{Declarations}

Conflict of interest The authors declare that there are no conflicts of interest associated with the work presented.

Human or animal rights The authors declare that no animals or human research has been conducted in this work.

Open Access This article is licensed under a Creative Commons Attribution 4.0 International License, which permits use, sharing, adaptation, distribution and reproduction in any medium or format, as long as you give appropriate credit to the original author(s) and the source, provide a link to the Creative Commons licence, and indicate if changes were made. The images or other third party material in this article are included in the article's Creative Commons licence, unless indicated otherwise in a credit line to the material. If material is not included in the article's Creative Commons licence and your intended use is not permitted by statutory regulation or exceeds the permitted use, you will need to obtain permission directly from the copyright holder. To view a copy of this licence, visit http://creativecommons.org/licenses/by/4.0/.

\section{References}

Abdulkhani A, Hosseinzadeh J, Ashori A et al (2014) Preparation and characterization of modified cellulose nanofibers reinforced polylactic acid nanocomposite. Polym Test 
35:73-79. https://doi.org/10.1016/j.polymertesting.2014. 03.002

Abushammala H, Hettegger H, Bacher M et al (2017) On the mechanism of the unwanted acetylation of polysaccharides by 1,3-dialkylimidazolium acetate ionic liquids: part 2the impact of lignin on the kinetics of cellulose acetylation. Cellulose 24:2767-2774. https://doi.org/10.1007/s10570017-1322-x

Alan KTL, Ada Pui Yan Hung (2017) Natural Fiber-Reinforced Biodegradable and Bioresorbable Polymer Composites

Amash A, Zugenmaier P (2000) Morphology and properties of isotropic and oriented samples of cellulose fibrepolypropylene composites. Polymer (guildf). https://doi. org/10.1016/S0032-3861(99)00273-6

Anugwom I, Mäki-Arvela P, Virtanen P et al (2012) Selective extraction of hemicelluloses from spruce using switchable ionic liquids. Carbohydr Polym 87:2005-2011. https://doi. org/10.1016/j.carbpol.2011.10.006

Arbelaiz A, Fernández B, Ramos JA, Mondragon I (2006) Thermal and crystallization studies of short flax fibre reinforced polypropylene matrix composites: effect of treatments. Thermochim Acta 440:111-121. https://doi. org/10.1016/j.tca.2005.10.016

Arwinfar F, Hosseinihashemi SK, Latibari AJ et al (2016) Mechanical properties and morphology of wood plastic composites produced with thermally treated beech wood. BioResources 11(1):1494-1504. https://doi.org/10.15376/ biores.11.1.1494-1504

Ashori A (2008) Wood-plastic composites as promising greencomposites for automotive industries! Bioresour Technol 99:4661-4667. https://doi.org/10.1016/j.biortech.2007.09. 043

Ashori A, Babaee M, Jonoobi M, Hamzeh Y (2014) Solvent-free acetylation of cellulose nanofibers for improving compatibility and dispersion. Carbohydr Polym. https://doi.org/ 10.1016/j.carbpol.2013.11.067

Berga L, Bruce I, Nicol TWJ et al (2020) Cellulose dissolution and regeneration using a non-aqueous, non-stoichiometric protic ionic liquid system. Cellulose 27:9593-9603. https:// doi.org/10.1007/s10570-020-03444-8

Bledzki A, Gassan J (1999) Composites reinforced with cellulose based fibres. Prog Polym Sci 24:221-274

Borysiak S (2010) A study of transcrystallinity in polypropylene in the presence of wood irradiated with gamma rays. J Therm Anal Calorim 101:439-445. https://doi.org/10. 1007/s10973-010-0780-2

Borysiak S (2012) Influence of wood mercerization on the crystallization of polypropylene in wood/PP composites. J Therm Anal Calorim 109:595-603. https://doi.org/10. 1007/s10973-012-2221-x

Borysiak S (2013a) Fundamental studies on lignocellulose/ polypropylene composites: effects of wood treatment on the transcrystalline morphology and mechanical properties. J Appl Polym Sci 127:1309-1322. https://doi.org/10. 1002/app.37651

Borysiak S (2013b) Influence of cellulose polymorphs on the polypropylene crystallization. J Therm Anal Calorim 113:281-289. https://doi.org/10.1007/s10973-013-3109-0

Borysiak S, Grząbka-Zasadzińska A, Odalanowska M et al (2018) The effect of chemical modification of wood in ionic liquids on the supermolecular structure and mechanical properties of wood/polypropylene composites. Cellulose 25:4639-4652. https://doi.org/10.1007/s10570018-1892-2

Cai Y, Petermann J, Wittich H (1997) Transcrystallization in fiber-reinforced isotactic polypropylene composites in a temperature gradient. J Appl Polym Sci 65:67-75. https:// doi.org/10.1002/(SICI)1097-4628(19970705)65:1\%3c67:: AID-APP9\%3e3.0.CO;2-O

Cao X, Zhu M, Fan F et al (2020) All-cellulose composites based on jute cellulose nanowhiskers and electrospun cellulose acetate (CA) fibrous membranes. Cellulose 27:1385-1391. https://doi.org/10.1007/s10570-01902880-5

Croitoru C, Patachia S (2016) Pro Ligno 12:28-33

Croitoru C, Varodi AM, Timar MC et al (2018) Wood-plastic composites based on HDPE and ionic liquid additives. J Mater Sci 53:4132-4143. https://doi.org/10.1007/ s10853-017-1826-7

Dányádi L, Móczó J, Pukánszky B (2010) Effect of various surface modifications of wood flour on the properties of PP/wood composites. Compos Part A Appl Sci Manuf 41:199-206. https://doi.org/10.1016/j.compositesa.2009. 10.008

Earle MJ, Seddon KR (2002) Ionic liquids: green solvents for the future. ACS Symp Ser 819:10-25. https://doi.org/10. 1021/bk-2002-0819.ch002

Ellis WD, O'dell JL (1999) Wood-polymer composites made with acrylic monomers, isocyanate, and maleic anhydride. J Appl Polym Sci. https://doi.org/10.1002/(SICI)10974628(19990919)73:12\%3c2493::AID-APP18\%3e3.0. $\mathrm{CO} ; 2-\mathrm{C}$

Feder-Kubis J, Zabielska-Matejuk J, Stangierska A et al (2019) Toward designing "sweet" ionic liquids containing a natural terpene moiety as effective wood preservatives. ACS Sustain Chem Eng 7:15628-15639. https://doi.org/10. 1021/acssuschemeng.9b03645

FitzPatrick M, Champagne P, Cunningham MF (2012) The effect of subcritical carbon dioxide on the dissolution of cellulose in the ionic liquid 1-ethyl-3-methylimidazolium acetate. Cellulose 19:37-44. https://doi.org/10.1007/ s10570-011-9607-y

French AD (2014) Idealized powder diffraction patterns for cellulose polymorphs. Cellulose 21:885-896. https://doi. org/10.1007/s10570-013-0030-4

Frone AN, Berlioz S, Chailan JF, Panaitescu DM (2013) Morphology and thermal properties of PLA-cellulose nanofibers composites. Carbohydr Polym 91:377-384. https:// doi.org/10.1016/j.carbpol.2012.08.054

Hasan M, Gopakumar DA, Arumughan V et al (2019) Robust superhydrophobic cellulose nanofiber aerogel for multifunctional environmental applications. Polymers (basel). https://doi.org/10.3390/polym11030495

Heinze T, Schwikal K, Barthel S (2005) Ionic liquids as reaction medium in cellulose functionalization. Macromol Biosci 5:520-525. https://doi.org/10.1002/mabi.200500039

Herrera-Díaz R, Sepúlveda-Villarroel V, Pérez-Peña N et al (2018) Effect of wood drying and heat modification on some physical and mechanical properties of radiata pine. Dry Technol 36:537-544. https://doi.org/10.1080/ 07373937.2017.1342094 
Hindeleh AM, Johnson DJ (1971) The resolution of multipeak data in fibre science. J Phys D Appl Phys. https://doi.org/ 10.1088/0022-3727/4/2/311

Hinner LP, Wissner JL, Beurer A et al (2016) Homogeneous vinyl ester-based synthesis of different cellulose derivatives in 1-ethyl-3-methyl-imidazolium acetate. Green Chem 18:6099-6107. https://doi.org/10.1039/ C6GC02005D

Hokkanen S, Bhatnagar A, Sillanpää M (2016) A review on modification methods to cellulose-based adsorbents to improve adsorption capacity. Water Res 91:156-173. https://doi.org/10.1016/j.watres.2016.01.008

Huddleston JG, Visser AE, Reichert WM et al (2001) Characterization and comparison of hydrophilic and hydrophobic room temperature ionic liquids incorporating the imidazolium cation. Green Chem 3:156-164. https://doi.org/10. 1039/b103275p

Ichazo MN, Albano C, González J et al (2001) Polypropylene/wood flour composites: treatments and properties. Compos Struct 54:207-214. https://doi.org/10.1016/ S0263-8223(01)00089-7

Inagaki T, Siesler HW, Mitsui K, Tsuchikawa S (2010) Difference of the crystal structure of cellulose in wood after hydrothermal and aging degradation: a NIR spectroscopy and XRD study. Biomacromol 11:2300-2305. https://doi. org/10.1021/bm100403y

Isik M, Sardon H, Mecerreyes D (2014) Ionic liquids and cellulose: dissolution, chemical modification and preparation of new cellulosic materials. Int J Mol Sci 15:11922-11940. https://doi.org/10.3390/ijms150711922

Johari AP, Kurmvanshi SK, Mohanty S, Nayak SK (2016) Influence of surface modified cellulose microfibrils on the improved mechanical properties of poly (lactic acid). Int $\mathrm{J}$ Biol Macromol 84:329-339. https://doi.org/10.1016/j. ijbiomac.2015.12.038

Joly C, Kofman M, Gauthier R (1996) Polypropylene/cellulosic fiber composites: chemical treatment of the cellulose assuming compatibilization between the two materials. J Macromol Sci - Pure Appl Chem. https://doi.org/10.1080/ 10601329608011023

Kaboorani A, Faezipour M, Ebrahimi G (2008) Feasibility of using heat treated wood in wood/thermoplastic composites. J Reinf Plast Compos 27:1689-1699. https://doi.org/10. 1177/0731684407084207

Kakko T, King AWT, Kilpeläinen I (2017) Homogenous esterification of cellulose pulp in [DBNH][OAc]. Cellulose 24:5341-5354. https://doi.org/10.1007/s10570-017-15215

Kalia S, Kaith BS, Kaur I (2009) Pretreatments of natural fibers and their application as reinforcing material in polymer composites-a review. Polym Eng Sci. https://doi.org/10. 1002/pen.21328

Kazayawoko M, Balatinecz JJ, Matuana LM (1999) Surface modification and adhesion mechanisms in woodfiberpolypropylene composites. J Mater Sci 34:6189-6199. https://doi.org/10.1023/A:1004790409158

Kilpeläinen I, Xie H, King A et al (2007) Dissolution of wood in ionic liquids. J Agric Food Chem 55:9142-9148. https:// doi.org/10.1021/jf071692e

Lenes M, Gregersen ØW (2006) Effect of surface chemistry and topography of sulphite fibres on the transcrystallinity of polypropylene. Cellulose 13:345-355. https://doi.org/10. 1007/s10570-006-9057-0

Li C, Wang Q, Zhao ZK (2008) Acid in ionic liquid: an efficient system for hydrolysis of lignocellulose. Green Chem 10:177-182. https://doi.org/10.1039/b711512a

Lotz B (1998) $\alpha$ and $\beta$ phases of isotactic polypropylene: a case of growth kinetics 'phase reentrency' in polymer crystallization. Polymer (guildf) 39:4561-4567. https://doi.org/ 10.1016/S0032-3861(97)10147-1

Mantanis GI (2017) Chemical modification of wood by acetylation or furfurylation: A review of the present scaled-up technologies. BioResources. https://doi.org/10.15376/ biores.12.2.4478-4489

Martins G, Antunes F, Mateus A, Malça C (2017) Optimization of a wood plastic composite for architectural applications. Procedia Manuf 12:203-220. https://doi.org/10.1016/j. promfg.2017.08.025

Michalska-Pozoga I, Rydzkowski T (2016) The effect of extrusion conditions for a screw-disk plasticizing system on the mechanical properties of wood-polymer composites (WPC). Polimery/Polymers 61(3):202-210. https://doi. org/10.14314/polimery.2016.202

Mohanty AK, Misra M, Hinrichsen G (2000) Biofibres, biodegradable polymers and biocomposites: an overview. Macromol Mater Eng 276-277:1-24. https://doi.org/10. 1002/(SICI)1439-2054(20000301)276:1\%3c1::AIDMAME1\%3e3.0.CO;2-W

Mollova A, Androsch R, Mileva D et al (2013) Crystallization of isotactic polypropylene containing beta-phase nucleating agent at rapid cooling. Eur Polym J 49:1057-1065. https:// doi.org/10.1016/j.eurpolymj.2013.01.015

Nachtigall SMB, Cerveira GS, Rosa SML (2007) New polymeric-coupling agent for polypropylene/wood-flour composites. Polym Test 26:619-628. https://doi.org/10.1016/j. polymertesting.2007.03.007

Ndiaye D, Diop B, Thiandoume C et al (2012) Morphology and Thermo Mechanical Properties of Wood/Polypropylene Composites. Polypropylene 4:415-428

Nuñez AJ, Sturm PC, Kenny JM et al (2003) Mechanical characterization of polypropylene-wood flour composites. J Appl Polym Sci 88:1420-1428. https://doi.org/10.1002/ app. 11738

Odalanowska M, Woźniak M, Ratajczak I et al (2021) Propolis and organosilanes as innovative hybrid modifiers in woodbased polymer composites. Materials (basel). https://doi. org/10.3390/ma14020464

Oksman K, Skrifvars M, Selin JF (2003) Natural fibres as reinforcement in polylactic acid (PLA) composites. Compos Sci Technol 63:1317-1324. https://doi.org/10.1016/ S0266-3538(03)00103-9

Ones DAEJ (1978) Fourier transform infrared spectra. Fourier Transform Infrared Spectra. https://doi.org/10.1016/ c2009-0-22072-1

Pandey KK (1999) A study of chemical structure of soft and hardwood and wood polymers by FTIR spectroscopy. J Appl Polym Sci 71:1969-1975. https://doi.org/10.1002/ (sici)1097-4628(19990321)71:12\%3c1969::aid-app6\% 3e3.0.co;2-d

Paukszta D, Borysiak S (2013) The influence of processing and the polymorphism of lignocellulosic fillers on the structure 
and properties of composite materials-A review. Materials (basel) 6:2747-2767. https://doi.org/10.3390/ma6072747

Pernak J, Zabielska-Matejuk J, Kropacz A, Foksowicz-Flaczyk $\mathrm{J}$ (2004) Ionic liquids in wood preservation. Holzforschung 58:286-291. https://doi.org/10.1515/HF.2004.044

Petrič M (2013) Surface modification of wood. Rev Adhes Adhes. https://doi.org/10.7569/raa.2013.097308

Plechkova NV, Seddon KR (2008) Applications of ionic liquids in the chemical industry. Chem Soc Rev 37:123-150. https://doi.org/10.1039/b006677j

Quan H, Li ZM, Yang MB, Huang R (2005) On transcrystallinity in semi-crystalline polymer composites. Compos Sci Technol 65:999-1021. https://doi.org/10.1016/j. compscitech.2004.11.015

Quillin DT, Caulfield DF, Koutsky JA (1993) Crystallinity in the polypropylene/cellulose system. I. Nucleation and crystalline morphology. J Appl Polym Sci 50:1187-1194

Rabiej S (1991) A comparison of two X-ray diffraction procedures for crystallinity determination. Eur Polym J 27:947-954. https://doi.org/10.1016/0014-3057(91)90038-P

Raka L, Bogoeva-Gaceva G (2017) Crystallization of polypropylene: application of differential scanning calorimetry part $\mathrm{i}$ isothermal and non-isothermal crystallization. Contrib Sect Nat Math Biotech Sci 29:69-87. https://doi.org/10.20903/csnmbs.masa.2008.29.1-2.13

Robin JJ, Breton Y (2001) Reinforcement of recycled polyethylene with wood fibers heat treated. J Reinf Plast Compos 20:1253-1262. https://doi.org/10.1106/JGKVEDG4-WYEW-1TT6

Rojas OJ (2016) Cellulose Chemistry and Properties: Fibers Nanocelluloses and Advanced Materials. Springer

Sabu Thomas PM, Visakh APM (2012) Advances in Natural Polymers: Composites and Nanocomposites. Springer

Salon MCB, Gerbaud G, Abdelmouleh M et al (2007) Studies of interactions between silane coupling agents and cellulose fibers with liquid and solid-state NMR. Magn Reson Chem. https://doi.org/10.1002/mrc.1994

Sandberg D, Kutnar A, Mantanis G (2017) Wood modification technologies - a review. Iforest 10:895-908. https://doi. org/10.3832/ifor2380-010

Shang W, Huang J, Luo H et al (2013) Hydrophobic modification of cellulose nanocrystal via covalently grafting of castor oil. Cellulose. https://doi.org/10.1007/s10570-0129795-0

Sun N, Rahman M, Qin Y et al (2009) Complete dissolution and partial delignification of wood in the ionic liquid 1-ethyl-3methylimidazolium acetate. Green Chem 11:646-655. https://doi.org/10.1039/b822702k

Swatloski RP, Spear SK, Holbrey JD, Rogers RD (2002) Dissolution of cellose with ionic liquids. J Am Chem Soc 124:4974-4975. https://doi.org/10.1021/ja025790m
Thakur VK, Thakur MK (2014) Processing and characterization of natural cellulose fibers/thermoset polymer composites. Carbohydr Polym 109:102-117. https://doi.org/10.1016/j. carbpol.2014.03.039

Thakur MK, Gupta RK, Thakur VK (2014a) Surface modification of cellulose using silane coupling agent. Carbohydr Polym. https://doi.org/10.1016/j.carbpol.2014.05.041

Thakur VK, Thakur MK, Gupta RK (2014) Review: Raw Natural Fiber-Based Polymer Composites. Int J Polym Anal Charact 19(3):256-71

Tserki V, Zafeiropoulos NE, Simon F, Panayiotou C (2005) A study of the effect of acetylation and propionylation surface treatments on natural fibres. Compos Part A: Appl Sci Manuf 36(8):1110-1118

Tufan M, Güleç T, Peşman E, Ayrilmis N (2016) Technological and thermal properties of thermoplastic. Bioresour 11(2):3153-3164. https://doi.org/10.15376/biores.11.2. 3153-3164

Varga J (1992) Supermolecular structure of isotactic polypropylene. J Mater Sci 27:2557-2579. https://doi.org/ 10.1007/BF00540671

Vitz J, Erdmenger T, Haensch C, Schubert US (2009) Extended dissolution studies of cellulose in imidazolium based ionic liquids. Green Chem 11:417-442. https://doi.org/10.1039/ b818061j

Wang C, Liu CR (1999) Transcrystallization of polypropylene composites: nucleating ability of fibres. Polymer (guildf) 40: 289-298. https://doi.org/10.1016/S0032-3861(98)00240-7

Wu J, Zhang J, Zhang H et al (2004) Homogeneous acetylation of cellulose in a new ionic liquid. Biomacromol 5:266-268. https://doi.org/10.1021/bm034398d

Yang Z, Peng H, Wang W, Liu T (2010) Crystallization behavior of poly( $\varepsilon$-caprolactone)/layered double hydroxide nanocomposites. J Appl Polym Sci 116:2658-2667. https://doi.org/10.1002/app

Zabielska-Matejuk J, Stangierska A, Kot M (2015) New ammonium- and 1,2,4-triazolium-based ionic liquids for wood preservation. J Wood Chem Technol 35:178-192. https://doi.org/10.1080/02773813.2014.909852

Zafeiropoulos NE, Baillie CA, Matthews FL (2001) Study of transcrystallinity and its effect on the interface in flax fibre reinforced composite materials. Compos Part A Appl Sci Manuf 32:525-543. https://doi.org/10.1016/S1359$835 X(00) 00058-0$

Zhu M, Cao Q, Liu B et al (2020) A novel cellulose acetate/poly (ionic liquid) composite air filter. Cellulose 27:3889-3902. https://doi.org/10.1007/s10570-020-03034-8

Publisher's Note Springer Nature remains neutral with regard to jurisdictional claims in published maps and institutional affiliations. 